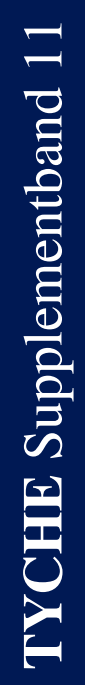

Supplementband 11

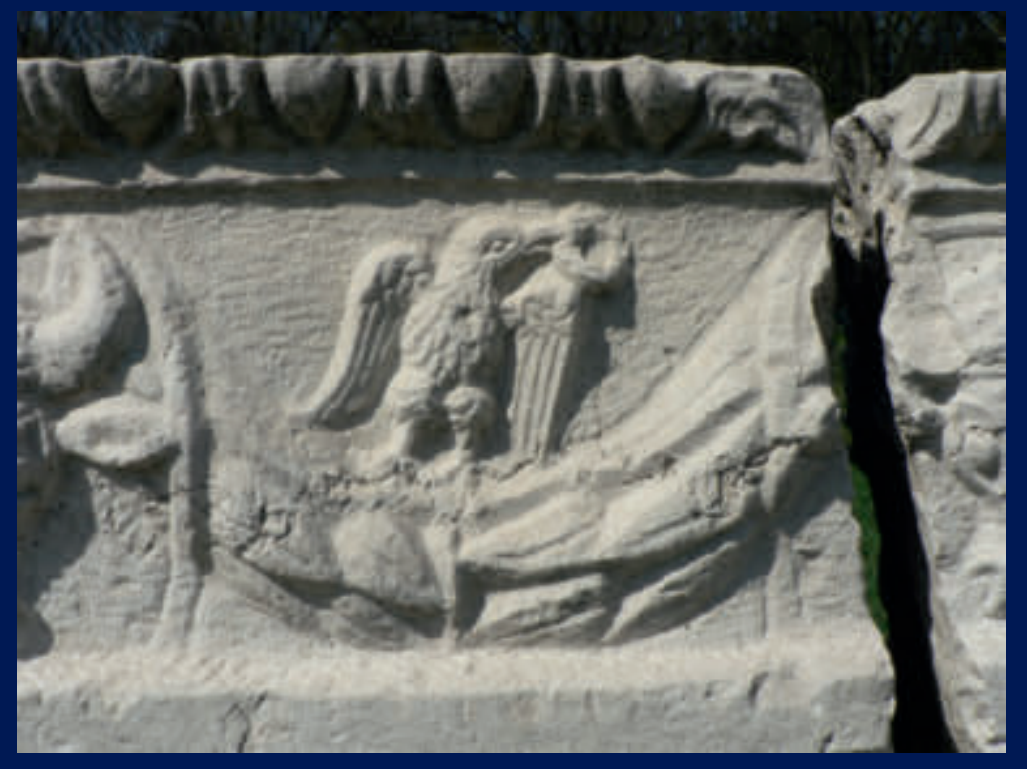

Ad ripam fluminis Danuvi

Papers of the 3rd International Conference on the Roman Danubian Provinces Vienna, 11th-14th November 2015

edited by

Fritz Mitthof - Chiara Cenati - Livio Zerbini

Wien 2021 


\title{
TYCHE Supplementband Nr. 11
}

\author{
Herausgegeben von: \\ TYCHE - Verein zur Förderung der Alten Geschichte in Österreich \\ Vertreten durch: \\ Fritz Mitthof, Chiara Cenati, Livio Zerbini
}

\section{Redaktion}

Franziska Beutler, Theresia Pantzer

\section{Auslieferung:}

Verlag Holzhausen GmbH, Leberstraße 122, A-1110 Wien

E-Mail: office@verlagholzhausen.at, Tel.: +43174095452

Online Bestellungen:

www.verlagholzhausen.at

https://shop.verlagholzhausen.at/hhshop/buch.wissenschaft/

Tyche/Supplementbaende.htm

Umschlag: Adler mit Lorbeerkranz auf Girlande. Detail vom Architrav des Fortuna-

Tempels auf dem Forum von Oescus (Gigen, Bulgarien), Zeit des Commodus

Foto: Nicolay Sharankov

Veröffentlicht mit Unterstützung des Austrian Science Fund (FWF): PUB 673-Z

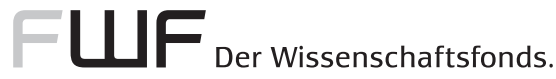

\section{Bibliografische Informationen der Österreichischen Nationalbibliothek und der Deutschen Nationalbibliothek}

Die ÖNB und die DNB verzeichnen diese Publikation in den Nationalbibliografien; detaillierte bibliografische Daten sind im Internet abrufbar. Für die Österreichische

Bibliothek: http://onb.ac.at, für die Deutsche Bibliothek: http://dnb.ddb.de.

Eigentümer und Verleger:

Verlag Holzhausen GmbH, Leberstraße 122, A-1110 Wien

Herausgeber:

TYCHE - Verein zur Förderung der Alten Geschichte in Österreich

c/o Institut für Alte Geschichte und Altertumskunde, Papyrologie und Epigraphik, Universität Wien, Universitätsring 1, A-1010 Wien.

E-Mail: hans.taeuber@univie.ac.at oder bernhard.palme@univie.ac.at

Gedruckt auf holz- und säurefreiem Papier

Verlagsort: Wien — Herstellungsort: Wien — Printed in Austria

ISBN: 978-3-902976-93-2 ISSN: 1992-514X

Copyright @ 2021 Verlag Holzhausen GmbH — Alle Rechte vorbehalten 